\title{
RETRACTION NOTE: The effect of marathon on mRNA expression of anti-apoptotic and pro-apoptotic proteins and sirtuins family in male recreational long-distance runners
}

Gabriella Marfe ${ }^{1^{*}}$, Marco Tafani ${ }^{2}$, Bruna Pucci ${ }^{2}$, Carla Di Stefano ${ }^{1}$, Manuela Indelicato ${ }^{2}$, Angela Andreoli ${ }^{3}$, Matteo Antonio Russo ${ }^{2,4}$, Paola Sinibaldi-Salimei ${ }^{1}$ and Vincenzo Manzi ${ }^{5}$

The authors have retracted the article [1]. Following publication of the article irregularities within the Northern blot figures were brought to the attention of the editors and subsequently confirmed by an investigation by the University of Rome Tor Vergata. We apologize to all affected parties.

\section{Author details}

'Department of Experimental Medicine and Biochemical Sciences, University of Rome "Tor Vergata" Via Montpellier 1, 00133, Rome, Italy. ${ }^{2}$ Department of Cellular and Molecular Pathology, IRCCS San Raffaele Pisana, Via dei

Bonacolsi snc, 00163, Rome, Italy. ${ }^{3}$ Human Nutrition Unit, University of Rome "Tor Vergata" Via Montpellier 1, 00133, Rome, Italy. ${ }^{4}$ Department of Experimental Medicine, La Sapienza University, Viale Regina Elena 324, 00161, Rome, Italy. ${ }^{5}$ School of Sport and Exercise Sciences, University of Rome Tor Vergata" Via Columbia s.n.c., 00133, Rome, Italy.

Received: 31 October 2013 Accepted: 31 October 2013

Published: 10 January 2014

\section{Reference}

1. Marfe G, Marco T, Pucci B, Di Stefano C, Indelicato M, Andreoli A, Russo MA, Sinibaldi-Salimei P, Manzi V: The effect of marathon on mRNA expression of anti-apoptotic and pro-apoptotic proteins and sirtuins family in male recreational long-distance runners. BMC Physiol 2010, 10:7.

\section{doi:10.1186/1472-6793-13-13}

Cite this article as: Marfe et al: RETRACTION: The effect of marathon on mRNA expression of anti-apoptotic and pro-apoptotic proteins and sirtuins family in male recreational long-distance runners. BMC Physiology 2013 13:13.

\footnotetext{
* Correspondence: gabriellamarfe@libero.it

'Department of Experimental Medicine and Biochemical Sciences, University of Rome "Tor Vergata" Via Montpellier 1, 00133, Rome, Italy
} reproduction in any medium, provided the original work is properly cited. The Creative Commons Public Domain Dedication waiver (http://creativecommons.org/publicdomain/zero/1.0/) applies to the data made available in this article, unless otherwise stated. 